\title{
Job demands and resources and their associations with early retirement intentions through recovery need and work enjoyment
}

\author{
Authors: \\ Bert Schreurs ${ }^{1}$ \\ Nele De Cuyper ${ }^{2}$ \\ I.J. Hetty van Emmerik ${ }^{1}$ \\ Guy Notelaers ${ }^{1}$ \\ Hans de Witte ${ }^{2}$ \\ Affiliations: \\ ${ }^{1}$ Department of Organization \\ and Strategy, Maastricht \\ University School of Business \\ and Economics, \\ The Netherlands \\ ${ }^{2}$ Research Group for \\ Work, Organizational and \\ Personnel Psychology, \\ University of Leuven, \\ Belgium \\ Correspondence to: \\ Bert Schreurs \\ Email: \\ b.schreurs@ \\ maastrichtuniversity.n

\section{Postal address:} \\ ${ }^{1}$ Department of Organization \\ and Strategy, Maastricht \\ University School of \\ Business and Economics, \\ Tongersestraat 53, 6211 LM \\ Maastricht \\ Dates: \\ Received: 18 Sept. 2009 \\ Accepted: 09 Dec. 2010 \\ Published: 23 May 2011 \\ How to cite this article: \\ Schreurs, B., De Cuyper \\ N., Van Emmerik, I.J.H., \\ Notelaers, G., \& De Witte, \\ H. (2011). Job demands \\ and resources and their \\ associations with early \\ retirement intentions \\ through recovery need and \\ work enjoyment. SA Journa \\ of Industrial Psychology/SA \\ Tydskrif vir Bedryfsielkunde, \\ 37(2), Art. \#859, 11 pages \\ doi:10.4102/sajip.v37i2.859
}

(C) 2011. The Authors. Licensee: OpenJournals Publishing. This work is licensed under the Creative Commons Attribution License.
Orientation: Job characteristics play a major role in shaping employees' early retirement decisions.

Research purpose: The objective of this study was to examine the mechanisms through which job characteristics associate with early retirement intention, using the Job Demands-Resources (JD-R) model as a theoretical framework.

Motivation of the study: Early retirement presents a threat to existing health and pension systems, and to organisational functioning. Therefore, it is important to examine how workrelated factors contribute to early retirement decisions.

Research design, approach and method: Two parallel processes were theorised to shape early retirement intention: a health impairment process (i.e. job demands $\rightarrow$ recovery need $\rightarrow$ early retirement intention) and a motivational process (i.e. job resources $\rightarrow$ work enjoyment $\rightarrow$ early retirement intention). Survey data were collected from a heterogeneous sample of 1812 older workers (age $>45$ ). Structural equation modeling was used to test the hypotheses.

Main findings: Job demands and job resources were both associated with work enjoyment, which was associated with early retirement intention. Recovery need did not add to the prediction of early retirement intention.

Practical/managerial implications: To retain older workers, companies should promote work conditions and practices that keep older workers motivated. Good health may be a necessary condition for retaining older workers, but it does not appear to be a sufficient one.

Contribution/value-add: The results suggest that - for early retirement intention - the motivational process is more prominent than the health impairment process.

\section{Introduction}

In most developed countries (e.g. UK, the Netherlands, New Zealand, Canada), the official age of retirement is 65 . However, the actual retirement age is well below this age (Organization for Economic Cooperation and Development [OECD], 2009). This has led to a growing contingent of early pensioners, which presents a threat not only to existing health and pension systems, but also to organisational functioning: early retirement may result in loss of valuable, organisationspecific knowledge that is costly and time-consuming to replace (Beehr, Glazer, Nielson, Farmer, 2000).

These problems have inspired a substantive amount of research concerning the factors associated with employees' intentions and, ultimately, their decision to retire early (e.g. Beehr et al., 2000; Higgs, Mein, Ferrie, Hyde, \& Nazroo, 2003). Most research in this respect has concerned individual difference factors, including demographics, self-rated health, financial status and attitudes toward retirement. In contrast, fewer studies have concerned associations between work-related factors and early retirement intentions, which is conspicuous given the abundant evidence that the work situation accounts for much variation in withdrawal from work (Bakker, Demerouti, De Boer, \& Schaufeli, 2003; Bakker, Demerouti, \& Schaufeli, 2003). Moreover, research examining the psychological processes through which these work-related factors associate with early retirement intentions is virtually nonexistent. To address this gap in the literature, researchers have recently called for studies examining the mechanisms underlying age-related phenomena, such as early retirement intentions (Cadiz, Truxillo, \& Sinclair, 2009). 


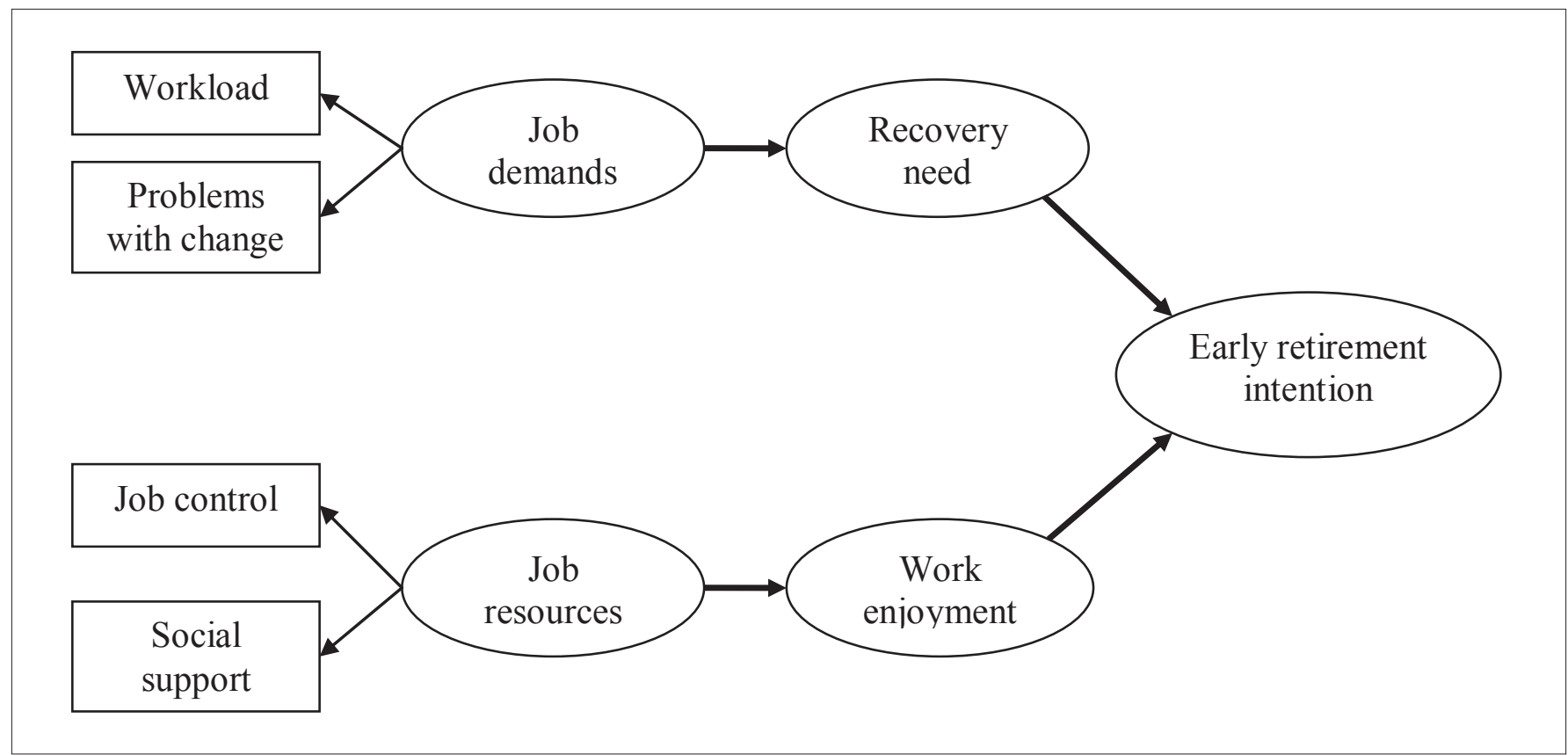

FIGURE 1: The job demands-resources model applied to early retirement intention.

Thus, the present study's aim is to respond to this call by examining whether and how work-related factors associate with early retirement. We focus on voluntary, rather than involuntary (e.g. due to employment constraints), early retirement because of its undesirable consequences for organisations and society. Using the job demands-resources (JD-R) model (Bakker \& Demerouti, 2007; Demerouti, Bakker, Nachreiner, \& Schaufeli, 2001), we tested the hypotheses that job demands (i.e. workload and problems with change at work) relate positively to early retirement intentions via a process of health impairment (i.e. recovery need) and that job resources (i.e. job control and social support) relate negatively to early retirement intentions via a motivational process (i.e. work enjoyment). Figure 1 presents our research model. These hypotheses were tested in a sample of 1812 Belgian workers aged 45 years and older. The situation in Belgium for the period 2002-2007 is that men retire, on average, at the age of 59.6 and women at 58.3 (OECD, 2009); hence, Belgium presents an exemplary case to study issues related to early retirement.

\section{Early retirement}

One of the key questions in retirement research is why people retire and why they retire early. Feldman (1994) defines retirement as 'the exit from an organizational position or career path of considerable duration, taken by individuals after middle age, and taken with the intention of reduced psychological commitment to work thereafter' (p. 287). According to this conceptualisation, retirement is the product of an informed decision-making process that unfolds over time, in which workers evaluate the overall utility of retirement before they reach the decision about whether to retire (Wang \& Shultz, 2010). Most of the research on retirement has focused on 'retirement as decisionmaking' and several theoretical frameworks have been used in association with this conceptualisation, including rational choice theory (Gustman \& Steinmeier, 1986), image theory (Beach \& Frederickson, 1989), role theory (Ashforth, 2001), theory of planned behaviour (Ajzen, 1991) and expectancyvalue theory (Vroom, 1964). Similarly, in this study we take a decision making approach to early retirement.

Early retirement then refers to the withdrawal from the labour force before the country's official retirement age, or the age at which the individual is entitled to a full old-age pension (Schils, 2008). Early retirement intention refers to the worker's perception concerning the desired or intended time span before retirement. Several authors (Beehr \& Bennett, 2007; Wang \& Shultz, 2010) note that early retirement intention is possibly one of the best predictors of actual retirement age. We focus upon early retirement intention, rather than age at the time of retirement: our basic argument is that we aim to hint at possible ways to prevent undesirable early retirement. The implication is that we target workers who deliberately choose or plan to retire early and not workers who are forced to retire early owing to, for example, organisational restructuring. Unlike age at time of retirement, early retirement intention captures this distinction.

\section{Factors influencing the retirement decision}

A number of factors influencing the retirement decision have been found. We briefly review these factors as they are relevant for early retirement as well. In line with Wang and Shultz (2010) we classify these factors as falling into three categories:

- microlevel personal factors

- mesolevel work-related factors

- macrolevel environmental factors. 
Microlevel personal factors: Not surprisingly, research consistently shows that the likelihood of retirement rises with age (e.g. Wang, Zhan, Liu, \& Shultz, 2008). Education is also related to retirement decisions, with highly educated employees being less likely to retire early (e.g. von Bonsdorff, Shultz, Leskinen, \& Tansky, 2009). Impaired health is another major factor influencing retirement decisions (e.g. Karpansalo, Manninen, Kauhanen, Lakka, \& Salonen, 2004). Health problems may cause employees to reconsider priorities, which to many means spending more time with family and friends, even if they could still perform at their jobs (Kim \& Feldman, 2000). Finally, several studies have shown that financial status and in particular financial distress, is an important driving force for people to continue working (e.g. Gruber \& Wise, 1999).

Mesolevel work-related factors: Research into the available literature shows that retirement decisions have been positively associated with a variety of work-related factors, including technological, managerial and cultural changes in the workplace, workload and physical demands. Conversely, retirement has been negatively associated with factors such as skill discretion, autonomy, opportunities for development, task clarity, job complexity, positive work climate and supervisory fairness (e.g. Sutinen, Kivimäki, Elovainio, \& Forma, 2005). The present study aims to extend this mesolevel perspective on retirement.

Macrolevel environmental factors: A number of macrolevel environmental factors have been found to influence retirement decisions. For instance, organisations can affect retirement decisions by their pension plans and other retirement policies (Beehr \& Bennet, 2007). Also, employees are more likely to retire when their organisation is facing financial hardship or downsizing (Hardy \& Hazelrigg, 1999). Furthermore, retirement decisions may be influenced by cultural norms about when to retire (Beehr \& Adams, 2003) and by negative stereotypes with regard to older workers (Posthuma \& Campion, 2009).

\section{Extending the work-related perspective on early retirement}

In the present study, we focus on the role of work-related factors in the early retirement decision-making process. We do so for two distinct reasons. Firstly, many of the frequently studied predictors of early retirement are tied to the individual and are fairly stable. Hence, they are difficult for organisations to manage or change. For instance, knowing that employees' decisions on when to retire are affected by their spouse's work status does not help organisations in any way to retain older workers. In contrast, our focus is upon aspects that are to a significant extent under the control of the organisation and that are, compared to individual factors, easier to change and to remedy. Conditional for such change and remedy are organisational prevention-based strategies, for example, job redesign to reduce work demands or participative decision making and skill training to increase job resources (see e.g. Couser, 2008). Whilst there are few studies about organisational interventions, the general belief is that such practices are beneficial to employees' well-being (Kompier, Geurts, Grundemann, Vink, \& Smulders, 1998). Accordingly, work-related factors in the form of job demands and job resources are, from a management perspective, more interesting to focus on.

Secondly, despite the progress made, work-related factors have received considerably less research attention compared to other factors (Beehr et al., 2000). In addition, most of the research on work-related predictors of retirement decisions has been conducted in a piecemeal fashion, without any cohesive theoretical framework. That is, few studies have started from a strong theoretical basis or testable hypotheses and they failed to explain the relationship between workrelated factors and early retirement intention. A noteworthy exception is the study by Elovainio et al. (2005), who used the well-known Job Demand-Control (JDC) model (Karasek, 1979) to predict early retirement intention. The authors found that workers' early retirement intention was positively associated with job demands and negatively with control in the workplace and that job control mitigated the effect of job demands on early retirement intention.

Extending this line of research, this study uses the Job Demands-Resources (JD-R) model (Demerouti et al., 2001) to predict early retirement intention. In line with the JD-R model, we argue that work-related factors may lead to early retirement intention through two relatively independent psychological processes:

- a health impairment process

- a motivational process.

Before discussing both processes and how they might be associated with early retirement, we first describe the main components of the JD-R model (see Bakker \& Demerouti, 2007, for an extensive narrative).

\section{The Job-Demands Resources model Job demands and resources}

The JD-R model (Bakker, Demerouti, De Boer et al., 2003; Demerouti et al., 2001) is an overarching model that can be applied to various occupational settings, irrespective of the particular demands and resources involved. The JD-R model assumes that every job has its own specific characteristics. These specific characteristics can be classified in two broad categories:

- job demands

- job resources.

Job demands refer to those physical, psychological, social or organisational aspects of the job that require sustained physical or psychological (cognitive and emotional) effort or skills and are therefore associated with certain physiological or psychological costs. Examples are high work pressure, an unfavorable physical environment, emotionally demanding interactions with clients (Bakker, Demerouti, Taris, Schaufeli, 
\& Schreurs, 2003) and issues related to job insecurity and change (Bakker, Demerouti, \& Schaufeli, 2003). Of particular relevance to this study are workload and change-related problems. Change-related problems refer to problems experienced with changes at the task level (e.g. 'do you find it difficult to adjust to changes in your tasks?', see van Veldhoven \& Meijman, 1994). The basis for this selection is twofold: firstly, it is grounded in the stereotyped idea that older workers are more resistant to change and less capable of adapting to an increasing workload (Posthuma \& Campion, 2009). Secondly, it builds on empirical data showing that workload and change-related problems contribute to the worker's decision to retire early (Luce, van Zwanenberg, Firth-Cozens, \& Tinwell, 2002).

Job resources refer to those physical, psychological, social or organisational aspects of the job that:

- are functional in achieving work goals

- reduce job demands and the associated physiological and psychological costs

- stimulate personal growth, learning and development.

Resources may be located at the level of (Bakker, Demerouti, Taris et al., 2003):

- the organisation at large (e.g. salary, career opportunities)

- interpersonal and social relations (e.g. supervisor and coworker support, team climate)

- the organisation of work (e.g. role clarity, participation in decision making)

- the task (e.g. skill variety, task identity, task significance, autonomy or performance feedback).

We selected job control and social support for three reasons. Firstly, job control and social support are core to most job characteristics models in work and organisational psychology, including, for example, Karasek's (1979) Job Demand-Control model. Secondly, the relationship between job control and social support and a host of outcomes in the domain of work stress and motivation has been demonstrated abundantly (e.g. Thoits, 1995). Thirdly, the assumption is that job control and social support contribute to early retirement decisions, which has been demonstrated in some studies (Elovainio et al., 2005).

\section{The health impairment process and early retirement}

The health impairment process can be summarised as follows: high job demands impose a great deal of strain on employees which may lead to energy depletion and short term fatigue, and in the long run, to serious health problems (Caplan, Cobb, French, Harrison, \& Pinneau, 1975). The relationship between job demands and various indicators of strain has been demonstrated abundantly (e.g. Caplan et al., 1975; Demerouti et al., 2001). We see need for recovery as yet another and fairly new indicator of strain in the JD-R model (Sonnentag \& Zijlstra, 2006). Recovery need relates to the individuals' experienced sense of urgency to take a break from a demanding work environment in order to replenish their resources (Sonnentag \& Zijlstra, 2006). Accordingly, several studies have shown that individuals who have been exposed to highly demanding work situations experience a higher need for recovery than individuals who have not been exposed to these situations (e.g. De Croon, Sluiter, Blonk, Broersen, \& Frings-Dresen, 2004; Sonnentag \& Zijlstra, 2006). Hence, we expect job demands to be positively associated with recovery need.

Taking this one step further, the JD-R model furthermore assumes that strain, also in the form of recovery need, may lead workers to withdraw from work. For example, in a study by De Croon et al. (2004), it was shown that truck drivers with a high need for recovery were more likely to voluntarily change jobs or even change careers. Withdrawal may also take the form of early retirement intention: health problems, as indicated by a high need for recovery, may interfere with a person's ability to perform effectively at work, at which point retirement becomes a welcome - if not the only - escape route. This reasoning is also in line with conservation of resources theory (Hobfoll, 1989), which posits that strain (i.e. high need for recovery) occurs when personal resources are threatened (i.e. by demands), and that workers seek to protect remaining resources. In this case, resources protection takes the form of early retirement. The relationship between health problems and early retirement can be understood in yet another way: namely, health problems may increase awareness that there is more to life than work, so that time spent outside work becomes even more valuable. The relationship between strain and health problems and aspects related to early retirement has been demonstrated in earlier studies. For example, Karpansalo et al. (2004), in a longitudinal study, found that self-assessed poor health was a strong predictor of early disability as well as a strong predictor of nonillnessbased pensioning. In another recent longitudinal study, Von Bonsdorff and colleagues (Von Bonsdorff, Huuhtanen, Tuomi, \& Seitsamo, 2010) showed that perceived poor health was positively associated with early retirement intentions. Similarly, we expect recovery need to be positively associated with early retirement. Hence, we propose that recovery need will mediate the relationship between job demands and early retirement intention. Accordingly, our first hypothesis reads:

- Hypothesis 1: The relationship between job demands and early retirement intention is mediated by recovery need.

\section{The motivational process and early retirement}

According to the JD-R model, job resources have motivational potential that leads to positive outcomes. Several studies in the realm of the JD-R model have shown that job resources associate positively with motivation-related concepts such as job satisfaction, work engagement and work-related flow (e.g. Bakker, 2008; Bakker, Hakanen, Demerouti, \& Xanthopoulou, 2007). In this study, we use work enjoyment as an indicator of motivation. In line with Spence and Robbins' (1992) original use of the term, we define work enjoyment as the extent to which people experience their work as pleasant and 
gratifying. As such, the concept of work enjoyment aligns and overlaps with similar concepts, such as job satisfaction (Spector, 1997) and work engagement (Bakker, Schaufeli, Leiter, \& Taris, 2008). We expect job resources to be positively associated with work enjoyment.

In a next step, motivation is assumed to relate negatively to withdrawal from work. Several studies in various contexts have shown that people are less likely to withdraw (more likely to persevere) when they enjoy what they are doing (Ryan \& Deci, 2000). For instance, employees working because of the inherent satisfaction and pleasure they experience are less likely to turnover (Richer, Blanchard, \& Vallerand, 2002) and to be absent from work (Steers \& Rhodes, 1978). Similar findings have been reported for early retirement intention: employees who are satisfied with their job are less inclined to retire early (Higgs et al., 2003). Accordingly, we assume work enjoyment to be negatively related to early retirement intention. Accordingly, our second hypothesis reads:

- Hypothesis 2: The relationship between job resources and early retirement intention is mediated by work enjoyment.

\section{Method}

\section{Participants}

A stratified sample of 5182 workers older than 45 was drawn from a large online panel $(N>100000)$ representative of the Belgian active working population with regard to age, branch, occupational position and region. Representativeness was guaranteed through the use of various techniques (e.g. diversification of the recruitment methods, comparing the online panel with regard to the population, the method of proportionally interlaced layered sample survey taking and the introduction of various control mechanisms). The threshold of 45 years was chosen in accordance with previous studies on early retirement intention in which an equivalent (or even younger) cut-off age was chosen (e.g. Elovainio et al., 2005). Panel members $(N=5182)$ received an email in which the purpose of the project was described, and in which they were requested to participate. Confidentiality and anonymity of their answers were emphasised and assured. For those who wished to participate, a link to an electronic questionnaire was included in the email; 1812 respondents completed and returned the questionnaire. Taking into account that $10 \%$ of the email addresses bounced back, the overall response rate was $38.8 \%$. This response rate was satisfactory (Baruch \& Holtom, 2008).

Of the respondents, 38\% were female. The respondents' mean age was 48 years $(\mathrm{SD}=3.6)$ and their mean organisational tenure was 18 years $(\mathrm{SD}=9.9)$. Furthermore, $82 \%$ of the respondents had a full-time job. Almost $90 \%$ had a permanent job, whilst $3 \%$ had a temporary job and about $7 \%$ were involved in another type of contract. In addition, $70 \%$ of the respondents had a daytime contract, 13\% worked in shifts, $11 \%$ had irregular working hours and approximately $2 \%$ worked during nights. The remainder of the respondents had other types of working schedules. About two-thirds worked in services, health sector or in public services. Approximately $23 \%$ worked in the industry or the construction sector, and $1 \%$ worked in the primary sector. Accordingly, the large majority of the respondents were white-collar workers $(N=1446 ; 80 \%)$.

\section{Instruments}

In terms of job resources, two job resources were included in the questionnaire, namely job control and social support. Both job resources were measured with scales taken from the Short Inventory to Monitor Psychosocial Hazards (SIMPH; Notelaers, De Witte, Van Veldhoven, \& Vermunt, 2007). The SIMPH is a recently developed and validated short version of the VBBA (Dutch Questionnaire on Experience and Evaluation of Work, Van Veldhoven \& Meijman, 1994).

Job control was measured with a 3-item scale. Respondents had to rate the extent to which they were able to influence decisions about their job; an example item is 'I can decide myself how I perform my work'. Items were scored on a 4-point Likert scale, ranging from 1 ('never') to 4 ('always'). Reliability (Cronbach's alpha) was 0.85 .

Social support was measured with four items. Respondents had to rate the level of support they received from their colleagues and superior; an example item is 'If necessary, I can ask my colleagues for help'. Items were scored on a 4-point Likert scale which ranged from 1 ('never') to 4 ('always'). Reliability (Cronbach's alpha) was 0.78 .

In terms of job demands, two job demands were included in the questionnaire, namely workload and problems with change at work. Workload was measured with three items from the SIMPH (Notelaers et al., 2007), referring to quantitative, demanding aspects of the job; an example item includes 'I have to work extra hard in order to complete a task'. Items were scored on a 4-point scale that ranged from 1 ('never') to 4 ('always'). Reliability (Cronbach's alpha) was 0.83 . Problems with change at work were assessed with a 3-item scale based on Van Veldhoven and Meijman (1994). Respondents had to rate the extent to which they were having difficulties with work-related changes; an example item includes 'Changes in my tasks pose difficulties to me' $(1=$ never, $4=$ always $)$. Reliability (Cronbach's alpha) was 0.81 .

Work enjoyment was measured with a 5-item scale taken from the SIMPH (Notelaers et al., 2007). The items tap the extent to which respondents find pleasure in working; an example item includes 'I really enjoy my work'. Items were rated with a dichotomous answering category (no $=0$; yes $=1$ ). The items were summed to form an index ranging from 0 to 5 , with high scores reflecting more work enjoyment. For a scale composed of dichotomous items, the most appropriate index of internal consistency is the Kuder-Richardson formula 20 (KR-20, Nunnally \& Bernstein, 1994). In the present sample, this equivalent to Cronbach's alpha was 0.85 . 
TABLE 1: Means, standard deviations, ranges and correlations amongst the study variables $(N=1812)$

\begin{tabular}{|c|c|c|c|c|c|c|c|c|c|c|}
\hline Variables & $M$ & SD & Range & 2 & 3 & 4 & 5 & 6 & 7 & 8 \\
\hline 1. Job demands & - & - & - & -0.44 & 0.74 & -0.37 & 0.33 & - & - & - \\
\hline 2. Job resources & - & - & - & - & -0.33 & 0.57 & -0.25 & - & - & - \\
\hline 3. Recovery need & 0.93 & 1.11 & $0-3$ & - & - & -0.33 & 0.26 & - & - & - \\
\hline 4. Work enjoyment & 4.01 & 1.54 & $0-5$ & - & -0.28 & - & -0.35 & - & - & - \\
\hline 5. Early retirement intention & 2.24 & 1.14 & $1-5$ & - & 0.20 & -0.31 & - & - & - & - \\
\hline 6. Workload & 2.45 & 0.67 & $1-4$ & - & 0.41 & -0.14 & 0.16 & - & - & - \\
\hline 7. Problems with change & 1.67 & 0.53 & $1-4$ & - & 0.27 & -0.27 & 0.23 & 0.29 & - & - \\
\hline 8. Job control & 2.56 & 0.73 & $1-4$ & - & -0.20 & 0.42 & -0.23 & -0.11 & -0.19 & - \\
\hline 9. Social support & 2.79 & 0.69 & $1-4$ & - & -0.24 & 0.39 & -0.17 & -0.20 & -0.19 & 0.55 \\
\hline
\end{tabular}

$M$, Mean; SD, Standard Deviation.

Correlations between the latent factors are above the diagonal; correlations between the observed variables are below the diagonal.

All correlations are significant at $p<0.001$ (2-tailed).

Recovery need was measured by means of three items taken from the SIMPH (Notelaers et al., 2007) about the severity and duration of symptoms which indicate that the respondent is not fully recovered from the effects of sustained effort during the working day; an example item includes 'Generally, I need more than an hour before I feel completely recuperated after work'. Items were rated with a dichotomous answering category (no $=0$; yes $=1$ ). The items were summed to form an index ranging from 0 to 3 , with high scores reflecting more recovery need. Reliability (KR-20) was 0.74 .

Early retirement intention was measured with four items similar to those used by Van Dam, Van der Vorst and Van der Heijden (2009) and were scored on a 5-point Likert scale which ranged from 1 ('strongly disagree') to 5 ('strongly agree'); an example item includes 'I intent to quit working before I am 65'. Reliability (Cronbach's alpha) was 0.90 .

\section{Plan of analysis}

Structural equation modeling (SEM) applying the maximumlikelihood method in LISREL 8.54 (Jöreskog \& Sörbom, 2002) was used to test the hypotheses. We first evaluated the measurement model using confirmatory factor analysis (CFA). We then continued with the structural models, as follows: Model 1 was the hypothesised model. It included paths from job demands to recovery need, from job resources to work enjoyment and from both recovery need and work enjoyment to early retirement intention. Model 2 accounted for possible relationships between job demands and work enjoyment and between job resources and recovery need. Although strictly speaking not hypothesised, some studies have provided evidence for such cross-links between job demands and motivational outcomes (e.g. Hakanen, Bakker, \& Demerouti, 2005), and between job resources and strain (e.g. Schaufeli \& Bakker, 2004). Model 3 accounted for possible direct relationships between job demands and resources and early retirement intention. Thus, Models 2 and 3 included two additional paths each. A potential criticism could be that age is a critical factor affecting the relationships in the structural model. For example, job demands may be more important amongst older workers, for whom early retirement is a realistic option. We therefore inspected whether the best fitting overall model was invariant across age groups through multiple group analysis. In all analyses, job demands and job resources were allowed to correlate.
Model fit was evaluated using several goodness-of-fit indices: the Root Means Square Error of Approximation (RSMEA), the Comparative Fit Index (CFI), the Standardized Root Means Square Residuals (SRMR) and the Non-Normed Fit Index (NNFI). RMSEA below 0.05 in combination with SRMR values below 0.09 indicate excellent fit, whereas values below 0.08 and 0.10 respectively indicate good fit $(\mathrm{Hu} \&$ Bentler, 1999). CFI and NNFI values larger than 0.90 indicate good fit, whereas values larger than 0.95 indicate excellent fit (Bentler, 1990). The chi-square difference test was used to compare nested models.

\section{Results \\ Preliminary analyses}

Table 1 presents the means, standard deviations, ranges and correlations of the study variables. All the relationships were in the expected direction. Job demands were moderately negatively correlated with job resources. Early retirement intention showed weak to moderate positive correlations with job demands and recovery need, and weak to moderate negative correlations with job resources and work enjoyment. Recovery need was strongly positively correlated with job demands and moderately negatively correlated with job resources. The reversed pattern was observed for work enjoyment; that is, work enjoyment was moderately negatively associated with job demands and strongly positively with job resources. Preliminary analyses were conducted to examine the associations between various demographic characteristics (e.g. gender, educational level and occupational status), recovery need, work enjoyment and early retirement intention. This was done by including these demographic controls in the structural equation model and by estimating their impact on the model components. The results of these analyses showed that the demographic variables were not significantly related to any of the model components and were therefore omitted from further analyses.

\section{Measurement model}

To test for the divergent validity of the latent factors, we estimated a full measurement model comprising the independent variables (i.e. job demands and job resources), the mediating variables (i.e. recovery need and work

1.The results of these analyses can be obtained from the first author upon request. 
TABLE 2: Goodness-of-fit indices of the hypothesised model and the alternative models $(N=1812)$.

\begin{tabular}{|c|c|c|c|c|c|c|c|c|c|c|}
\hline Model & Type & $\chi^{2}$ & $d f$ & RMSEA & SRMR & CFI & NNFI & $\begin{array}{l}\text { Model } \\
\text { comparisons }\end{array}$ & $\Delta \chi^{2}$ & $\Delta d f$ \\
\hline M1 & JD-R model & 552.04 & 99 & 0.05 & 0.054 & 0.98 & 0.97 & - & - & - \\
\hline M2 & Cross-link model & 522.26 & 97 & 0.049 & 0.047 & 0.98 & 0.97 & $\mathrm{M} 1-\mathrm{M} 2$ & 29.78 & 2 \\
\hline M3 & Partial mediation model & 532.43 & 97 & 0.05 & 0.052 & 0.98 & 0.97 & $\mathrm{M} 1-\mathrm{M} 3$ & 19.61 & 2 \\
\hline M4 & Partial mediation, partial cross-link model & 504.02 & 97 & 0.048 & 0.044 & 0.98 & 0.97 & $\mathrm{M} 1-\mathrm{M} 4$ & 48.02 & 2 \\
\hline M5 & Final model & 507.75 & 98 & 0.048 & 0.44 & 0.98 & 0.97 & $\mathrm{M} 4-\mathrm{M} 5$ & 3.73 & 1 \\
\hline
\end{tabular}

df, Degrees of freedom; RMSEA, Root Mean Square Error of Approximation; SRMR, Standardised Root Mean Square Residuals; CFI, Comparative Fit Index; NNFI, Non-normed Fit Index.

enjoyment) and the dependent variable (i.e. early retirement intention). Job demands and job resources were represented by their respective job characteristics. The latent constructs of recovery need and work enjoyment were indexed by three and five items respectively. Finally, the latent construct of early retirement intention was indicated by its four items. Estimation of the measurement model with 16 observed variables and five latent variables yielded good fit of the model to the data, $\chi^{2}(94)=501.26, p<.001$; RMSEA $=0.05$; $\mathrm{SRMR}=0.04 ; \mathrm{CFI}=0.98$ and NNFI $=0.97$. All observed variables had significant $(p<0.001)$ loadings (ranging from 0.49 to 0.86 ) on their latent factor (mean $\chi=0.72$ ). A reliable measurement model was thus obtained.

\section{Structural model}

Next, the hypothesised JD-R model (M1) was tested. This model related job demands and job resources to recovery need and work enjoyment, respectively, which in turn were associated with early retirement intention. As is shown in Table 2, M1 showed good to excellent fit to the data. The pathcoefficients from job demands to recovery need $(\gamma=0.77, p<$ $0.001)$, and from recovery need to early retirement intention $(\gamma=0.18, p<0.001)$ were positive and significant, indicating that the higher the job demands reported by the employees, the higher their need for recovery, and the stronger their intention to retire early (cf. Hypothesis 1). In addition, the path-coefficient from job resources to work enjoyment was positive and significant $(\gamma=0.60, p<0.001)$, whereas the coefficient of the path from work enjoyment to early retirement intention was negative and significant $(\gamma=-0.32, p$ $<0.001)$. This means that more job resources coincided with more work enjoyment, which in turn was associated with a decreased intention to retire early (cf. Hypothesis 2).

In order to test the alternative hypothesis that job demands are also related to work enjoyment, and job resources to recovery need, we included both diagonal paths in the model (cross-link model - M2). Compared to the previous model, adding both paths resulted in a significant improvement of the model fit, $\Delta \chi^{2}(2)=29.87, p<0.001$. However, only job demands showed a significant and negative relationship with work enjoyment $(\gamma=-0.19, p<0.001)$. Importantly, the model in which the paths from job demands to recovery need and to work enjoyment were constrained to be equal was significantly worse than $M 2, \Delta \chi^{2}(1)=258.02, p<0.001$.

The second alternative model included additional direct relationships between job demands and early retirement intention and between job resources and early retirement intention (partial mediation model - M3). Compared to M1, adding both direct paths resulted in a significant improvement of the model fit, $\Delta \chi^{2}(2)=19.61, p<0.001$. The direct path from job demands to early retirement intention was positive and significant $(\gamma=0.32, p<0.001)$, indicating a direct relationship. Including this path resulted in a nonsignificant association between recovery need and early retirement intention $(\gamma=-0.08)$. Hence, recovery need does not seem to carry the relationship between job demands and early retirement intention. Conversely, the direct path from job resources to early retirement intention was nonsignificant $(\gamma=-0.03)$, suggesting full mediation by work enjoyment. The results of a Sobel test confirmed that job resources had an indirect effect on early retirement intention through work enjoyment $(z=6.71, p<0.001)$.

Based on the series of SEM analyses, it seems that the proposed JD-R model fit well to the data, even though we found some additional paths that were not predicted. Specifically, in addition to the hypothesised relationships, job demands predicted early retirement intention directly as well as indirectly through work enjoyment. Therefore, a third alternative model was tested that included both additional paths (partial mediation, partial cross-link model - M4). Compared to M1, adding both paths resulted in a significant improvement of the model fit, $\Delta \chi^{2}(2)=48.02, p<0.001$. All paths were significant $(p<0.001)$, except for the path from recovery need to early retirement intention.

M4 was then trimmed by removing the non-significant path between recovery need and early retirement intention, which did not alter the model fit, $\Delta \chi^{2}(1)=3.73, n s$. The final model (M5), which explained $19 \%$ of the variance in early retirement intention, is displayed graphically in Figure 2.

Finally, to examine whether the observed relationships are invariant across sub-samples of 'older' workers, we conducted a multiple-group analysis estimating the same model as in Figure 2, for workers younger than 50 years and workers of 50 and older. This threshold was chosen as in Belgium the age of 50 is the earliest possible retirement age (Jousten, Lefèbvre, Perelman, \& Pestieau, 2008). The analysis showed no significant differences between the two age groups, suggesting that workers older than 45 constitute a homogeneous group.

\section{Discussion}

The aim of this study was to investigate employees' intentions to retire early in the light of job-related factors derived from 


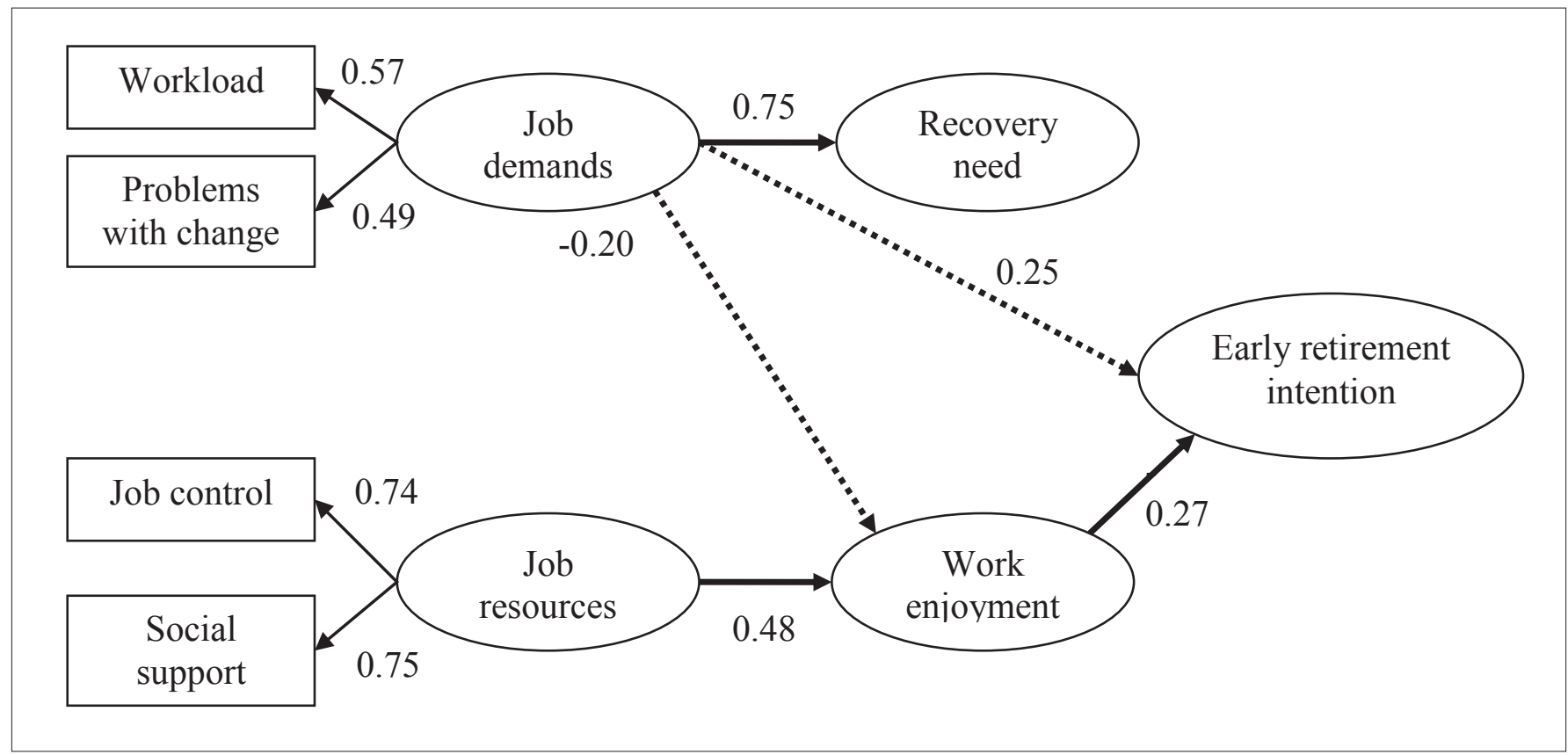

FIGURE 2: The final model (standardised path coefficients). Solid lines refer to predicted relationships. Dashed lines refer to non-predicted relationships.

the JD-R model (Bakker \& Demerouti, 2007; Demerouti et al., 2001). That is to say, we used early retirement intentions as the ultimate outcome of the health-impairment process and the motivational process that are central to the JD-R model.

The motivational process is conditional upon a relationship between job resources and indicators of motivation, typically work engagement; a relationship that was replicated also in this study for work enjoyment. Taking this one step further, motivation is then assumed to relate negatively to withdrawal behavior; for example, turnover intentions in the study by Schaufeli and Bakker (2004), or absence frequency in the study by Bakker, Demerouti, De Boer et al. (2003). We showed that withdrawal may also refer to early retirement intentions. This hints at mediation, so that work enjoyment carries the relationship between job resources and early retirement intentions, which was demonstrated in this study (Hypothesis 2).

The health impairment process assumes a relationship between job demands and strain. Examples of strain indicators are burnout or job dissatisfaction, or, in this study, recovery need. Strain, in turn, associates positively with withdrawal. Evidence comes from the studies by Geurts, Schaufeli and de Jonge (1998) and De Croon et al. (2004). However, we did not find such a relationship between strain and early retirement intentions, implying that recovery need did not mediate the relationship between job demands and early retirement intention. One explanation could be that recovery need is only a first stage to health impairment with few long-term effects. Instead, recovery need may concern short-term effects of a working day (Sluiter, De Croon, Meijman, \& Frings-Dresen, 2003) that do not translate into long-term effects. Hence, a high need for recovery might not be alarming enough for older workers to set in motion the exit process. In this respect, other age-related physical and cognitive changes, including vision and hearing loss, increase in blood pressure, musculoskeletal problems and memory decline, might pose a more serious threat to employees' functioning, and therefore, might be more strongly associated with early retirement (Lund \& Borg, 1999).

In addition, we also established a cross-link from job demands to work enjoyment, so that job demands related negatively to work enjoyment, and a direct positive link from job demands to early retirement intention. An important route for future research is to further investigate these relationships, particularly from a theoretical point of view. Perhaps job demands are perceived differently according to age, so that job demands have a stronger negative effect on work affect and attitudes or intentions amongst older workers. For instance, young workers may see the same combination of high resources and high job demands as more challenging and hence more positive, as compared to older workers.

This study makes several contributions to the literature. Firstly, we have extended the outcome side of the JD-R model. We concentrated on a special type of job withdrawal, namely early retirement, as there is substantial evidence that the work situation accounts for much variation in withdrawal from work (Bakker, Demerouti, De Boer et al., 2003; Bakker, Demerouti, \& Schaufeli, 2003) and that early retirement in our graying society is increasingly important. Concentrating on this special type of job withdrawal, we found altogether, that our results largely aligned with the predictions made in the JD-R model. The variance explained in early retirement intention was attributed to:

- a direct path from job demands to early retirement intention 
- an indirect path from job resources $\rightarrow$ work enjoyment $\rightarrow$ early retirement intention

- $\quad$ an indirect path from job demands $\rightarrow$ work enjoyment $\rightarrow$ early retirement intention.

Secondly, by using the JD-R model we have extended the work-related perspective on early retirement. Workrelated antecedents of early retirement have received some research attention, but many of these studies have been conducted without strong theoretical foundation, limiting understanding of the processes that explain early retirement decisions. Thirdly, it is important to note that for early retirement intention the associations within the model are different than was anticipated. The current results indicate that - for early retirement intention - the motivational process is more prominent than the health impairment process. In addition, when examining the antecedents of early retirement intention the emphasis is on the direct positive effects of the motivational processes and not on the buffering role of job resources on the relationship between demands and negative outcomes. This has important implications for organisations striving to keep their older employees. They should facilitate the motivational processes that are so important to lower early retirement. For instance, by re-examining job contents of older workers and redesigning their jobs with an emphasis on adding job resources instead of the traditional approach of decreasing job demands.

\section{Limitations and suggestions for further research}

The cross-sectional design was perhaps the most important limitation in this study; the implication is that we cannot draw causal inferences. Note, however, that our predictions are in line with theoretical arguments and that causal relationships from job demands to strain, from job resources to motivation and from strain and motivation to withdrawal have been demonstrated in previous studies (e.g. De Jonge et al., 2001). Perhaps a more serious concern is that we could not account for possible reciprocal relationships, for example, from work enjoyment to job resources or from recovery need to job demands. Such reciprocal relationships fit the notion of gain and loss spirals that have been demonstrated in studies in the realm of the JD-R model (see e.g. Demerouti, Bakker, $\&$ Bulters, 2004). Such spirals would suggest that the process described in this study reinforces itself. Thus, future research on early retirement decision making may profit from using longitudinal designs that account for possible cycles.

A second limitation could be that our data was based on self-reports, which may present some risks associated with common method variance. In this respect, we followed many of the recommendations for questionnaire design proposed by Podsakoff, MacKenzie, Lee and Podsakoff (2003). We furthermore showed through confirmatory factory analysis that the items loaded on their respective factors, as intended. In addition, a 5-factor model in which each item loaded on its respective factor showed a better fit to the data than a single factor model, $\Delta \chi^{2}(10)=6133.67, p<0.001$.
Another limitationis that our samplewas fairly heterogeneous. This posed some challenges regarding the selection of specific job demands and resources. Indeed, every job comes with specific demands and resources, and this specificity was not accounted for in this study. We selected the job demands and resources that may have particular resonance for the group of older workers rather than for a specific job category to overcome this limitation. Furthermore, having a heterogeneous and representative sample presents some obvious advantages, amongst them the idea that results can be generalised to the broader population.

Finally, we recruited workers from Belgium; a country where early retirement is relatively common. According to Eurostat, in 2001, Belgium was in the leading group of European countries with respect to early retirement. This is partly due to the generosity of the social security and pension systems in place in Belgium (Jousten et al., 2008). This particular setting may have influenced the results. Hence, future studies could explore the generalisability of our results to other cultures and countries.

\section{Practical implications}

This study has important practical implications because it indicates that creating and sustaining a healthy workforce by no means guarantees that older employees will continue working until their official retirement age. Good health may be a necessary condition for retaining older workers, but it certainly does not appear to be a sufficient one. Just as their younger colleagues, older employees want to enjoy their work, and their level of enjoyment seems to play a major role in shaping their early retirement intentions. Hence, to retain older workers, companies should promote work conditions and practices that keep older workers happy and motivated. The practices could involve job re-design interventions by implementing extended job control and discretion over how older workers schedule and perform their job tasks, or assistance of older workers in maintaining and extending social networks. The latter may be particularly important as older employees often lack opportunities to form special, intimate peer relationships at work that provide high psychosocial support (Maurer, 2007). In this regard, mentoring may be especially valuable for inclusion of older workers. It offers a new challenge to older workers and protects them from becoming isolated.

\section{Conclusion}

In this study, job demands and job resources were both associated with work enjoyment, which, in turn, was associated with older workers' intention to retire early. In addition, a direct link was established between job demands and early retirement intention. Recovery need did not add to the prediction of early retirement intention. These results suggest that, in order to retain older employees, it is not just sufficient to create a healthy workforce. Rather, organisations should continuously strive for measures that increase older workers' happiness and work pleasure. 


\section{References}

Ajzen, I. (1991). The theory of planned behavior. Organizational Behavior and Human Decision Processes, 50, 179-211. doi:10.1016/0749-5978(91)90020-T

Ashforth, B. (2001). Role transitions in organizational life: An identity-based perspective. Mahwah, NJ: Lawrence Erlbaum.

Bakker, A.B. (2008). The work-related flow inventory: Construction and initial validation of the WOLF. Journal of Vocational Behavior, 72, 400-414. doi:10.1016/j. jvb.2007.11.007

Bakker, A.B., \& Demerouti, E. (2007). The Job Demands-Resources model: State of the art. Journal of Managerial Psychology, 22, 309-328. doi:10.1108/02683940710733115

Bakker, A.B., Demerouti, E., De Boer, E., \& Schaufeli, W.B. (2003). Job demands and job resources as predictors of absence duration and frequency. Journal of Vocational Behavior, 62, 341. doi:10.1016/S0001-8791(02)00030-1

Bakker, A.B., Demerouti, E., \& Schaufeli, W.B. (2003). Dual processes at work in a call centre: An application of the job demands-resources model. European Journal of Work and Organizational Psychology, 12, 393-417. doi:10.1080/13594320344000165

Bakker, A.B., Demerouti, E., Taris, T.W., Schaufeli, W.B., \& Schreurs, P. (2003) A multi-group analysis of the job demands-resources model in four hom care organizations. International Journal of Stress Management, 10, 16-38. doi:10.1037/1072-5245.10.1.16

Bakker, A.B., Hakanen, J.J., Demerouti, E., \& Xanthopoulou, D. (2007). Job resources boost work engagement, particularly when job demands are high. Journal of educational psychology, 99, 274-284. doi:10.1037/0022-0663.99.2.274

Bakker, A.B., Schaufeli, W.B., Leiter, M.P., \& Taris, T. (2008). Work engagement: An emerging concept in occupational health psychology. Work \& Stress, 22, 187-200. doi:10.1080/02678370802393649

Baruch, Y., \& Holtom, B.C. (2008). Survey response rate levels and trends in organizational research. Human Relations, 61, 1139-1160. doi:10.1177/0018726708094863

Beach, L.R., \& Frederickson, J.R. (1989). Image theory: An alternative description of audit decisions. Accounting, Organizations, and Society, 14, 31-56. doi:10.1016/0361-3682(89)90036-6

Beehr, T.A., \& Adams, G.A. (2003). Introduction and overview of current research and thinking about retirement. In G.A. Adams \& T.A. Behr (Eds.), Retirement research: Reasons, processes and results (pp. 1-5). New York: Springer.

Beehr, T.A., \& Bennett, M.M. (2007). Examining retirement from a multi-level perspective. In K.S. Shultz \& G.A. Adams (Eds.), Aging and work in the 21st century perspective. In K.S. Shultz \& G.A. Adams (Eds.), Aging and work
(pp. 277-302). Mahwah, NJ: Lawrence Erlbaum Associates.

Beehr, T.A., Glazer, S., Nielson, N.L., \& Farmer, S.J. (2000). Work and nonwork predictors of employees' retirement ages. Journal of Vocational Behavior, 57, 206-225. doi:10.1006/jvbe.1999.1736 Bentler, P.M. (1990). Comparative fit indexes in structural models
Psychological Bulletin, 107, 238-246. PMid:2320703

Cadiz, D., Truxillo, D.M., \& Sinclair, R.R. (2009, April). Subjective age, core selfevaluations, and workplace outcomes among nurses. In D. Cadiz \& D. M. Truxillo (Chair), Perceptions of age in the workplace: U.S. and E.U. perspectives. Symposium conducted at the $24 \mathrm{th}$ Annual Conference of the Society for Industrial and Organizational Psychology, New Orleans, LA

Caplan, R.D., Cobb, S., French, J.R.P., Jr., Harrison, R.V., \& Pinneau, S.R., Jr. (1975) Job demands and worker health: Main effects and occupational differences. Washington, DC: US Department of Health, Education, and Welfare.

Couser, G.P. (2008). Challenges and opportunities for preventing depression in the workplace: A review of the evidence supporting workplace factors and interventions. Journal of Occupational and Environmental Medicine, 50, 411-427. doi:10.1097/JOM.0b013e318168efe2, PMid:18404014

De Croon, E.M., Sluiter, J.K., Blonk, R.W.B., Broersen, J.P.J., \& Frings-Dresen, M.H.W. (2004). Stressful work, psychological job strain, and turnover: A 2-year prospective cohort study of truck drivers. Journal of Applied Psychology, 89, 442-454. doi:10.1037/0021-9010.89.3.442, PMid:15161404

De Jonge, J., Dorman, C., Janssen, P.P.M., Landeweerd, J.A., \& Nijhuis, F.J.N. (2001) Testing reciprocal relationships between job characteristics and psychological well-being: A cross-lagged structural equation model. Journal of Occupational and Organizational Psychology, 74, 29-46. doi:10.1348/096317901167217

Demerouti, E., Bakker, A.B., \& Bulters, A.J. (2004). The loss spiral of work pressure, work-home interference and exhaustion. Reciprocal relations in a threewave study. Journal of Vocational Behavior, 64, 131-149. doi:10.1016/S0001 8791(03)00030-7

Demerouti, E., Bakker, A.B., Nachreiner, F., \& Schaufeli, W.B. (2001). The job demandsresources model of burnout. Journal of Applied Psychology, 86, 499-512. doi:10.1037/0021-9010.86.3.499, PMid:11419809

Elovainio, M., Forma, P., Kivimäki, M., Sinervo, T., Sutinen, R., \& Laine, M. (2005) Job demands and job control as correlates of early retirement thoughts in Finnish social and health care employees. Work and Stress, 19, 84-92. doi:10.1080/02678370500084623

Feldman, D.C. (1994). The decision to retire early: A review and conceptualization Academy of Management Review, 19, 285-311. doi:10.2307/258706

Geurts, S.A.E., Schaufeli, W.B., \& de Jonge, de C.G. (1998). Burnout and intention to leave among mental health care workers. Journal of Clinical and Social Psychology, 17, 341-362. doi:10.1521/jscp.1998.17.3.341
Gruber, J., \& Wise, D.A. (1999). Social security and retirement around the world. Research in Labor Economics, 18, 1-40. doi:10.1016/S0147-9121(99)18018-X

Gustman, A.L., \& Steinmeier, T.L. (1986). A structural retirement model. Econometrica, 54, 555-584. doi:10.2307/1911308

Hakanen, J., Bakker, A., \& Demerouti, E. (2005). How dentists cope with their job demands and stay engaged: the moderating role of job resources. European journal of Oral Sciences, 113, 479-487. doi:10.1111/j.1600-0722.2005.00250.x PMid:16324137

Hardy, M.A., \& Hazelrigg, L. (1999). A multilevel model of early retirement decisions among autoworkers in plants with different futures. Research on Aging Special Issue: Multilevel Models, 21, 275-303.

Higgs, P., Mein, G., Ferrie, J., Hyde, M., \& Nazroo, J. (2003). Pathways to early retirement: structure and agency in decision-making among British civil servants. Ageing \& Society, 23, 761-778. doi:10.1017/S0144686X03001326

Hobfoll, S.E. (1989). Conservation of resources: A new attempt at conceptualizing stress. American Psychologist, 44, 513-525. doi:10.1037/0003-066X.44.3.513, PMid:2648906

Hu, L., \& Bentler, P.M. (1999). Cutoff criteria for fit indexes in covariance structure analysis: Conventional criteria versus new alternatives. Structural Equation Modeling, 6, 1-55. doi:10.1080/10705519909540118

Jöreskog, K.G., \& Sörbom, D. (2002). LISREL (Version 8.54) [Computer software]. Lincolnwood, IL: Scientific Software International, Inc.

Jousten, A., Lefèbvre, M., Perelman, S., \& Pestieau, P. (2008). The effects of early retirement on youth unemployment: The case of Belgium. (IMF Working paper 08/30)

Karasek, R.A. (1979). Job demands, job decision latitude, and mental strain: Implications for job redesign. Administrative Science Quarterly, 24, 285-308. doi:10.2307/2392498

Karpansalo, M., Manninen, P., Kauhanen, J., Lakka, T.A., \& Salonen, J.T. (2004) Perceived health is a strong predictor of early retirement. Scandinavian Journal of Work, Environment \& Health, 30, 287-292. PMid:15458011

Kim, S., \& Feldman, D.C. (2000). Working in retirement: The antecedents of bridge employment and its consequences for quality of life in retirement. Academy of Management Journal, 43, 1195-1210. doi:10.2307/1556345

Kompier, M.A.J., Geurts, S.A.E., Grundemann, R.W.M., Vink, P., \& Smulders, P.G.W. (1998). Cases in stress prevention: The success of a participative and
stepwise approach. Stress Medicine, 14, 155-168. doi:10.1002/(SICI)1099stepwise approach. Stress Medicine, 14, 155-1
1700(199807)14:3<155::AID-SMI773>3.0.CO;2-C

Luce, A., van Zwanenberg, T., Firth-Cozens, J., \& Tinwell, C. (2002). What might encourage later retirement among general practitioners? Journal of Management in Medicine, 16, 303-310. doi:10.1108/02689230210445112, Management in
PMid:12463646

Lund, T., \& Borg, V. (1999). Work environment and self-related health as predictors of remaining in work 5 years later among Danish employees 35-59 years of age. Experimental Aging Research, 25, 429-434. doi:10.1080/036107399243904, PMid:10553527

Maurer, T.J. (2007). Employee development and training issues related to the aging workforce. In K.S. Shultz \& G.A. Adams (Eds.), Aging and work in the 21st century (pp. 163-178). Mahwah, NJ: Lawrence Erlbaum Associates.

Notelaers, G., De Witte, H., Van Veldhoven, M., \& Vermunt, J.K. (2007). Construction and validation of the Short Inventory to Monitor Psychosocial Hazards. Arbeidsgezondheidszorg \& Ergonomie, Band XLIV, 11-17.

Nunnally, J.C., \& Bernstein, I.H. (1994). Psychometric theory. (3rd edn.). New York: McGraw-Hill.

OECD. (2009). Society at a Glance 2009 - OECD Social Indicators. Retrieved March 7, 2010, from www.oecd.org/els/social/indicators/SAG.

Podsakoff, P.M., MacKenzie, S.B., Lee, J.Y., \& Podsakoff, N.P. (2003). Common method biases in behavioral research: A critical of the literature and recommended remedies. Journal of Applied Psychology, 88, 879-903. doi:10.1037/0021 9010.88.5.879, PMid:14516251

Posthuma, R.A., \& Campion, M.A. (2009). Age stereotypes in the workplace: Common stereotypes, moderators, and future research directions. Journal of Management 35, 158-188. doi:10.1177/0149206308318617

Richer, S.F., Blanchard, C., \& Vallerand, R.J. (2002). A motivational model of work turnover. Journal of Applied Social Psychology, 32, 2089-2113. doi:10.1111/j.1559-1816.2002.tb02065.x

Ryan, R.M., \& Deci, E.L. (2000). Self-determination theory and the facilitation of intrinsic motivation, social development, and well-being. American Psychologist, 55, 68-78. doi:10.1037/0003-066X.55.1.68, PMid:11392867

Schaufeli, W.B., \& Bakker, A.B. (2004). Job demands, job resources, and their relationship with burnout and engagement: A multi-sample study. Journal of Organizational Behavior, 25, 293-315. doi:10.1002/job.248

Schils, T. (2008). Early retirement in Germany, the Netherlands, and the United Kingdom: A longitudinal analysis of individual factors and institutional regimes. European Sociological Review, 24, 315-329. doi:10.1093/esr/jcn009

Sluiter, J.K., de Croon, E.M., Meijman, T.F., \& Frings-Dresen, M.H.W. (2003). Need for recovery from work related fatigue and its role in the development and prediction of subjective health complaints. Occupational and Environmental Medicine, 60 i62-i70. doi:10.1136/oem.60.suppl_1.i62, PMCid:1765724

Sonnentag, S., \& Zijlstra, F.R.H. (2006). Job characteristics and off-job activities as predictors of need for recovery, well-being, and fatigue. Journal of Applied Psychology, 91, 330-350. doi:10.1037/0021-9010.91.2.330, PMid:16551187

Spector, P. (1997). Job satisfaction. Application, assessment, causes, and consequences. Thousand Oaks: Sage. 
Spence, J.T., \& Robbins, A.S. (1992). Workaholism: Definition, measurement, and preliminary results. Journal of Personality Assessment, 58, 160-178. doi:10.1207/ p15327752jpa5801_15, PMid:16370875

Steers, R.M., \& Rhodes, S.R. (1978). Major influences on employee attendance: A process model. Journal of Applied Psychology, 63, 391-407. doi:10.1037/00219010.63.4.391

Sutinen, R., Kivimäki, M., Elovainio, M., \& Forma, P. (2005). Associations between stress at work and attitudes towards retirement in hospital physicians. Work and Stress, 19, 177-185. doi:10.1080/02678370500151760

Thoits, P.A. (1995). Stress, coping, and social support processes: Where are we? What next? Journal of Health and Social Behavior, 35, 53-79. doi:10.2307/2626957

Van Dam, K., Van der Vorst, J.D.M., \& Van der Heijden, B.I.J.M. (2009). Employees' intentions to retire early. Journal of Career Development, 35, 265-289. doi:10.1177/0894845308327274

Van Veldhoven, M., \& Meijman, T.F. (1994). The measurement of psychosocial job demands with a questionnaire (VBBA). Amsterdam: NIA.
Von Bonsdorff, M.E., Shultz, K.S., Leskinen, E., \& Tansky, J. (2009). The choice between retirement and bridge employment: A continuity and life course perspective. International Journal of Aging and Human Development 69, 79-100. doi:10.2190/AG.69.2.a

Von Bonsdorff, P.E., Huuhtanen, P., Tuomi, K., \& Seitsamo, J. (2010). Predictors of employees' early retirement intentions: An 11-year longitudinal study. Occupational Medicine, 60, 94-100. doi:10.1093/occmed/kqp126, PMid:19734239

Vroom, V.H. (1964). Work and motivation. New York: Wiley.

Wang, M., \& Shultz, K.S. (2010). Employee retirement: A review and recommendations for future investigation. Journal of Management, 36, 172-206. doi:10.1177/0149206309347957

Wang, M., Zhan, Y., Liu, S., \& Shultz, K. (2008). Antecedents of bridge employment: A longitudinal investigation. Journal of Applied Psychology, 93, 818-830. doi:10.1037/0021-9010.93.4.818, PMid:18642986 